\title{
ANALYSIS OF 3D TECHNOLOGY IMPACT ON STEM BASED COURSES; SPECIFICALLY INTRODUCTION TO ENGINEERING COURSES.
}

\section{Prof. Oscar Antonio Perez, University of Texas, El Paso}

Mr. Oscar Perez received his B.S. and Masters in Electrical Engineering from the University of Texas at El Paso with a special focus on data communications. Awarded the Woody Everett award from the American Society for engineering education August 2011 for the research on the impact of mobile devices in the classroom. He is currently pursuing a PhD in Electrical and Computer Engineering. Mr. Perez has been teaching the Basic Engineering (BE) - BE 1301 course for over 7 years. Lead the design for the development of the new Basic Engineering course (now UNIV 1301) for engineering at UTEP: Engineering, Science and University Colleges. Developed over 5 new courses, including UTEP technology \& society core curriculum classes specifically for incoming freshman with a STEM background. Mr. Perez was awarded the 2014 "University of Texas at El Paso award for Outstanding Teaching". Mr. Perez has eight years of professional experience working as an Electrical and Computer Engineer providing technical support to faculty and students utilizing UGLC classrooms and auditoriums. Mr. Perez is committed to the highest level of service to provide an exceptional experience to all of the UGLC guests. Mr. Perez strongly believes that by providing exceptional customer service that UGLC patrons will return to make use of the various services the university offers. Mr. Perez enjoys working on the professional development of the students' employees at the UGLC. He shares with his student employees his practical experience in using electrical engineering concepts and computer technologies to help in everyday real-world applications. Mr. Perez has worked with the UTeach program at UTEP since its creation to streamline the transition process for engineering students from local area high schools to college by equipping their teachers with teaching strategies and technologies each summer. Oscar enjoys teamwork, believes in education as a process for achieving life-long learning rather than as a purely academic pursuit. He currently works on maintaining, upgrading and designing new computer classroom systems. Mr. Perez is inspired because he enjoys working with people and technology in the same environment.

\section{Mr. Mike Thomas Pitcher, University of Texas, El Paso}

Mike Pitcher is the Director of Academic Technologies at the University of Texas at El Paso. He has had experience in learning in both a traditional university program as well as the new online learning model, which he utilizes in his current position consulting with faculty about the design of new learning experiences. His experience in technology and teaching started in 1993 as a student lab technician and has continued to expand and grow over the years, both technically as well as pedagogically. Currently he works in one of the most technically outstanding buildings in the region where he provides support to students, faculty, and staff in implementing technology inside and outside the classroom, researching new engineering education strategies as well as the technologies to support the 21st century classroom (online and face to face). He also has assisted both the campus as well as the local community in developing technology programs that highlight student skills development in ways that engage and attract individuals towards STEAM and STEM fields by showcasing how those skills impact the current project in real-world ways that people can understand and be involved in. As part of a university that is focused on supporting the 21 st century student demographic he continues to innovate and research on how we can design new methods of learning to educate both our students and communities on how STEM and STEAM make up a large part of that vision and our future.

\section{Mr. Pedro Arturo Espinoza, University of Texas, El Paso}

Pedro worked in the manufacturing industry as a Quality Control Engineer for some years before acquiring his current position as an Instructional Technologist at the University of Texas at El Paso (UTEP). For over 10 years in this role, he has worked with a team of managers that oversee various learning environments and systems in the Academic Technologies Department at UTEP. He leads a group of more than 40 multidisciplinary student employees that help support a wide range of technologies for classrooms and other learning spaces, including videoconferencing rooms. In addition to teaching a Foundations of Engineering course, Pedro also provides technology training on Mac OS X, CISCO networking and various 
other technology topics. He also enjoys the role of social media coordinator for Academic Technologies to showcase the department's services and the dedicated students and staff members who work there. Pedro received his Bachelor of Science degree in Electrical Engineering and a Master of Science in Engineering with a concentration in Engineering Education from UTEP.

\section{Mr. Hugo Gomez, University of Texas, El Paso}

Mr. Hugo Gomez works as an Instructional Technologist at the University of Texas at El Paso, he is focused on expanding the professional and technical skill sets of our students and faculty community to better prepare them for the world of technology today and tomorrow. He works alongside a wide assortment of students, faculty and staff on campus to make sure their technology toolsets are up to date. Furthermore, Hugo provides workshops to over half of the student population at UTEP and as such, has been instrumental in providing the behind the scenes support to all these courses. Mr. Gomez also collaborates in the Learning Lab team to explore and implement new educational strategies in the classroom. Mr. Gomez has a Masters Degree in Engineering Education from The University of Texas at El Paso. He has participated in the UTEACH summer program as a Technology Instructor in which he provided workshops on website design, movie creation and computer networking. In addition, Mr. Gomez teaches UNIV1301 Foundations of Engineering, were students learn academic, personal and engineering skills, among many other abilities that help them understand their opportunities and responsibilities as engineering students.

\section{Mrs. Herminia Hemmitt, University of Texas, El Paso}

Mrs. Herminia Hemmitt is part of the Learning Environments team in Academic Technologies at The University of Texas at El Paso. She is responsible for coordinating classroom technology upgrades and implementations to ensure projects deadlines and anticipated goals are met. Her educational background in organizational and corporate communication is utilized in consultations with faculty and staff about their learning environments in order to correctly match them to appropriate learning spaces or adapt existing spaces to meet their pedagogical and technological needs. Her focus is on the specific user to make sure that classroom needs, technical needs, and/or event needs at met.

\section{Mr. Randy Hazael Anaya, University of Texas, El Paso}

Randy Anaya, Instructional Technologist at the University of Texas at El Paso. Received a BFA degree in Graphic Design with a minor in Multimedia design from the Universidad Autónoma de Ciudad Juarez, Mexico. Received a BA in Media Advertising degree at UTEP and is currently enrolled as a Master of Interdisciplinary Studies with an emphasis on the use of art and technology in teaching and learning. Randy works on research and development of applying the creative process to workshops and trainings to foster student engagement; he has worked extensively in trainings on media production software like iBooks editor to promote student e-portfolios. He is also doing extensive research and deployment of emerging technologies to redefine the class environment, mentoring and excellence through student interaction.

\section{Dr. Peter Golding, University of Texas, El Paso}

Professor, Metallurgical \& Materials Engineering

\section{Hector Erick Lugo Nevarez, University of Texas, El Paso}

Mr. Hector Lugo works as a Student Technology Success Coordinator at The University of Texas at El Paso. He holds a B.S. in Electrical Engineering. He is currently enrolled as a Master of Science with a Major in Electrical Engineering. His motivation and passion pushes him into research in wireless communication, especially in Bluetooth Low Energy and Near Field Communication as well as building projects and fostering innovation with faculty and staff members. As part of the Learning Environments division, the idea to develop, oversee and assess engaging students to expand their knowledge and creativity by innovating new technologies application for Engineering Education is currently under way to engage the university and the community. Concluding, Mr. Lugo's ambition is to encourage students to focus in science, technology and engineer abilities in order to expand their professional potential. 


\section{ANALYSIS OF THE IMPACT OF 3D TECHNOLOGY IN STEM- BASED COURSES; SPECIFICALLY INTRODUCTION TO ENGINEERING COURSES.}

The impact of new technologies on teaching and learning engineering is important to study and understand for various reasons, including: (1) the pervasive use of technology tools by students, and (2) the rapidly increasing use of technology tools in schools and college classrooms, as new devices that balance cost, functionality and portability and shift the use of computing devices from personal purposes to mainstream course applications. We present the results of studying the impact of using one such device, a 3D printer, on students' academic performance via a subset of course objectives for an introductory engineering course. This paper inherently focuses on student perceived value and learning impact (comprehension of learning outcomes). Sets of 3D design projects were assigned to students along with focused activities to gauge differences in comprehension of learning outcomes. Student perceived value of using a 3D printer for a class was also (measured, tested and evaluated) within a learning environment featuring $21^{\text {st }}$ century demographics for the science, technology, engineering, and mathematics fields. The effect of a 3D printer in the STEM classroom was focused on two key indicators: academic impact and student perceived value. Student perceived value was measured via a student attitudinal survey (Likert scale). This survey was completed after the 3D printing technology was introduced in the course. The survey was managed through an independent third-party testing entity. The assessment for the comprehension component of the study focused on two cohorts of students. All cohorts of students were taught the same way from the commencement of the semester until the time of the first course exam. This was done to limit and account for the possible variance of class grades. At the beginning of week eight, the first 3D project was distributed for the second cohort of students. The usage of the 3D printer in class assignments was focused on maximizing the impact of student learning on the following class areas: class assignments, homework, quizzes and exams. Variances between the cohorts were assessed as part of the second and third course exams. This research project yielded data in a field that has not been previously explored within the associated demographic environment. The complete analysis on the student comprehension and student perceived value were analyzed and the results obtained are included here within this paper.

\section{INTRODUCTION}

Throughout history there have been many attempts to incorporate different technologies in the classroom. ${ }^{1}$ When compared, some of these technologies have seen more success than others. ${ }^{2}$ The most commonly used classroom technologies are: PowerPoint ${ }^{3}$ software, computers, chalkboards, web posting of materials, paper handouts, transparencies, laptops, overhead projectors, classroom computers, online course management programs, whiteboards, online 
discussion groups, document cameras, tablet PCs, streaming videos, clickers, VCRs, Acrobat Connect software, and PDAs. ${ }^{4}$ Currently, however, the impact and effects in the classroom of one of the newest technologies available to the consumer and educational markets, the 3D printer, has not been extensively researched. While there are ongoing research efforts to measure the impact of 3D printers in the classroom, most are focused on a specific area of engineering. This is one of the first research studies done on an engineering class for all the engineering disciplines. This presents a challenge, as currently only limited research is being done within the first year of engineering and science fields of first-year college students whose demographics compare to those found at The University of Texas at El Paso (UTEP). This research specifically focuses on the impact the "3D printer" and "3D printing projects" have on a subset of objectives for a first year engineering class that represents the university demographics. ${ }^{5}$ This research will measure students' perceived value of using this technology (specifically the 3D Printer) inside and outside the classroom. This type of study has not been previously done given the demographics, content, and subject matter involved. This research provides important information for the engineering and engineering education fields..

The evolution of classroom technology is variable and the rate at which it evolves changes from device to device. A key example of such is the board. Boards have been around for a long time and have evolved into chalkboards, then into whiteboards, and then some of the functions of the boards were transferred to projectors and computers, thus creating smart boards. ${ }^{4}$ Would the new generation of students positively perceive the impact of a 3D printer as a beneficial tool for their education? This research uses the 3D printer to provide a physical 3D model representation of some the most commonly used concepts in an introduction to engineering course. Some of these concepts are: critical thinking, basic and intermediate computer skills, three-dimensional vectors, computer simulation, systems engineering and systems thinking, time management, research techniques, presentation skills and project management techniques. Will the impact of the use of a $3 \mathrm{D}$ printer in the classroom outweigh its cost in this framework? This is one of our primary questions.

\section{MATERIALS AND METHODS}

This research began the summer of 2013. After creating an infrastructure of support, it was incorporated as part of the UNIV 1301 Foundations of Engineering classes ( 3 sections of the same class). The classes participating in this research consisted of similar enrollment numbers. The first class consisted of twenty-six students (Class B); the second class had twenty-two students (Class C), and the third class had twenty-four students (Class D). Students were enrolled mainly in core curriculum classes such as Foundations of Engineering, Pre-calculus, History, and Political Science. All of the students in these classes were first semester freshmen and the class distribution represents the university demographics ${ }^{5}$. This type of enrollment reduced outside factors that influence student learning and allowed the 3D printer to be one of few variables.

The materials used for this research consisted of the Makerbot Replicator Desktop Printer (fifth generation with a build volume of $25.2 \mathrm{~L} \mathrm{x} 19.9 \mathrm{~W}$ x $15.0 \mathrm{H}$ and capable of printing 456 cubic inches) and the teaching material already used to teach the class. The teaching materials for the class consisted of a group websites created using Microsoft SharePoint, a series of PowerPoint and 
Keynote presentations, individual quizzes and team quizzes in text format. The class materials also included several in-class active learning activities focused on engineering design, teamwork, and problem solving.

The experiments conducted to analyze student perceived value and learning impact are detailed below. As an overview, following is how the experiments were conducted. Academic learning performance in four classes was compared to determine the learning impact on students when the 3D printer was introduced. This was done after teaching the same class content to all classes. For the second experiment, a post-attitudinal survey was given to all of the students of the classes that used the 3D printer. This same procedure will be followed for the second year of the research.

Training was an integral part of the student project as was attending different technology workshops provided by the Learning Environments (LE) area within the Academic Technologies (AT) department at UTEP. LE works directly with students and faculty to research and prototype technology in educational spaces. Furthermore, students were given a web space and training in different types of software (iWeb, iMovie, Inventor Fusion) to record and present their projects.

\section{UNIV 1301: Foundations of Engineering Class Format}

UNIV 1301: Foundations of Engineering is a face-to-face class that meets three hours per week and is a 3-hour credit class. An attendance policy was enforced, which allows no more than three absences for the entire semester. The grading areas of the class include homework, quizzes \& projects, exam I, and II, and a student presentation. The material covered in the class focuses on these four areas equally: basic engineering and science concepts, math applications in engineering, entering student life activities (focuses on the engineering department), and engineering professions. The material of the class is divided into 3 segments of six weeks each. An examination is given at the end of segment 1 and segment 2. Finally, after the last six weeks a comprehensive final exam is also given to all students. In this first iteration of the 3D technology impact research, the 3D printing projects and exercises were only included on the second six weeks of the course.

\section{Class Content Research - First Six Weeks}

For the first six weeks of the course, the first part of the experiment was to teach the four classes without the $3 \mathrm{D}$ printer projects and then compare their performance. This was done to generate a baseline for the differences in comprehension of content between the classes. At this point, for simplicity, the class where the 3D printer was not used will be referred to as "class A", the classes where the 3D printer was used will be referred to as "Class B", "Class C" and "Class D". As a precautionary measure to prevent students from passing-on exams from one year to the next, students were not allowed to keep their exams and question order was varied. A grading scale of 0 to 100 was used for the exam. The average of Class A on exam one was 77.9. The average of Class B on exam one was 82.5. The average of Class $C$ on exam one was 85.0. The average of Class D on exam one was 72.31. Class A outperformed Class B by 4.57 points on average, Class C outperformed Class A by 7.07 points and Class D outperformed Class A by -5.62 points. All of these results are shown in Table 1.

\section{Class Content Research - Second Six Weeks}

For the second six weeks all of the students in Classes B, C, and D started working on a 3D printer design of a bridge that covers the same concepts as in Class A. Class A continued the course 
without any 3D printer exercises. Class B, Class C, and Class D students used the class website to download class materials and upload assignments among other things. Several of these assignments included drafts of 3D original designs and reports on the progress of the 3D design project. After the second six weeks the average on exam 2 for Class $A$ was 59.7; the average for Class $B$ was 65.50, the average for Class $C$ was 86.83 and the average for Class $D$ was 79.21. Class D outperformed Class A by 19.51 points, Class C outperformed Class A by 27 points, and Class $B$ by 5.8 points on average.

\section{Experiment 2 - Student Perceived Value}

An attitudinal survey was administered at the end of the semester to each of the classes using 3D technology. The survey was administered at the 16-week mark (end of the semester). The survey administrators were independent from the instructor and no feedback was given to the instructor at any point in time while the class was going on. The instructor was able to see the results after the course concluded at the end of the semester and final grades were submitted to avoid any biasing from the instructor. After the class concluded the attitudinal surveys were analyzed and the results can be found in the results section below.

\section{RESULTS}

Below in Table 1 are the results of the class performance presented as an average for each class on each of the exams administered during the semester, along with the final course average. Figures 1, 2 and 3 show the grade distribution of the courses on all three exams in an overlapping manner to facilitate the comparison.

\begin{tabular}{|c|c|c|c|c|c|}
\hline Class areas & Class A & Class B & Class C & Class D & Difference from Class A \\
\hline $\begin{array}{c}\text { Exam I (no 3D } \\
\text { Technology all classes) }\end{array}$ & 77.93 & 82.50 & 85.00 & 73.31 & $+4.57,+7.07,-5.62$ \\
\hline Exam II & 59.7 & 65.50 & 86.83 & 79.21 & $+5.8,+27.13,+19.51$ \\
\hline
\end{tabular}

Table 1. Average academic performance of the four classes 


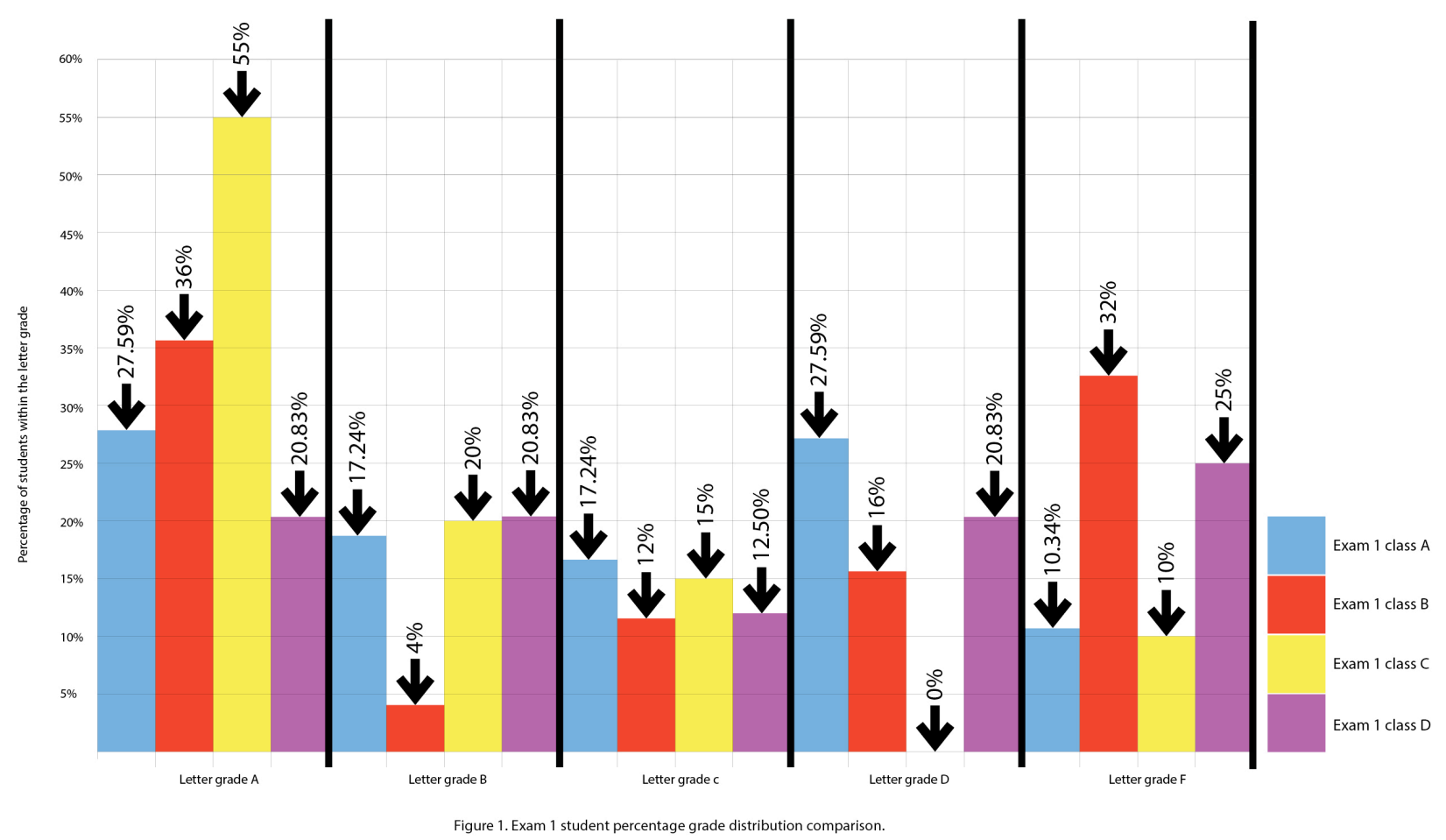

Figure 1. Exam 1 student percentage grade distribution comparison

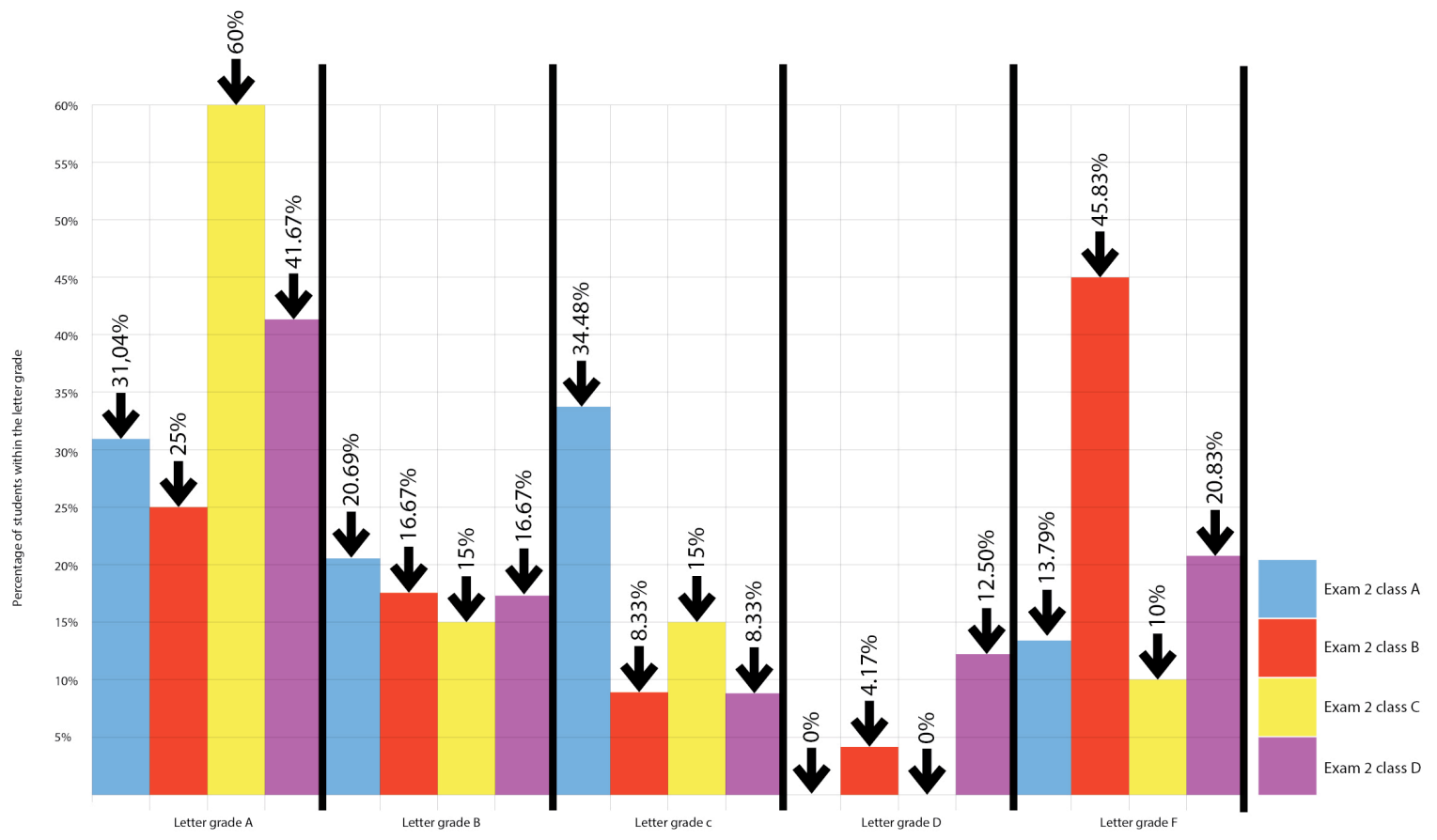

Figure 2. Exam 2 student percentage grade distribution comparison 
These results and their impact are discussed extensively in the Discussion section. Figures 3, 4 and 5 below display several important trends that were discovered with this survey instrument. The questions shown below are not all the questions asked to the students, but are the ones that show the greatest impact by the project. For a complete listing of the survey instrument please visit http://3dprint.at.utep.edu

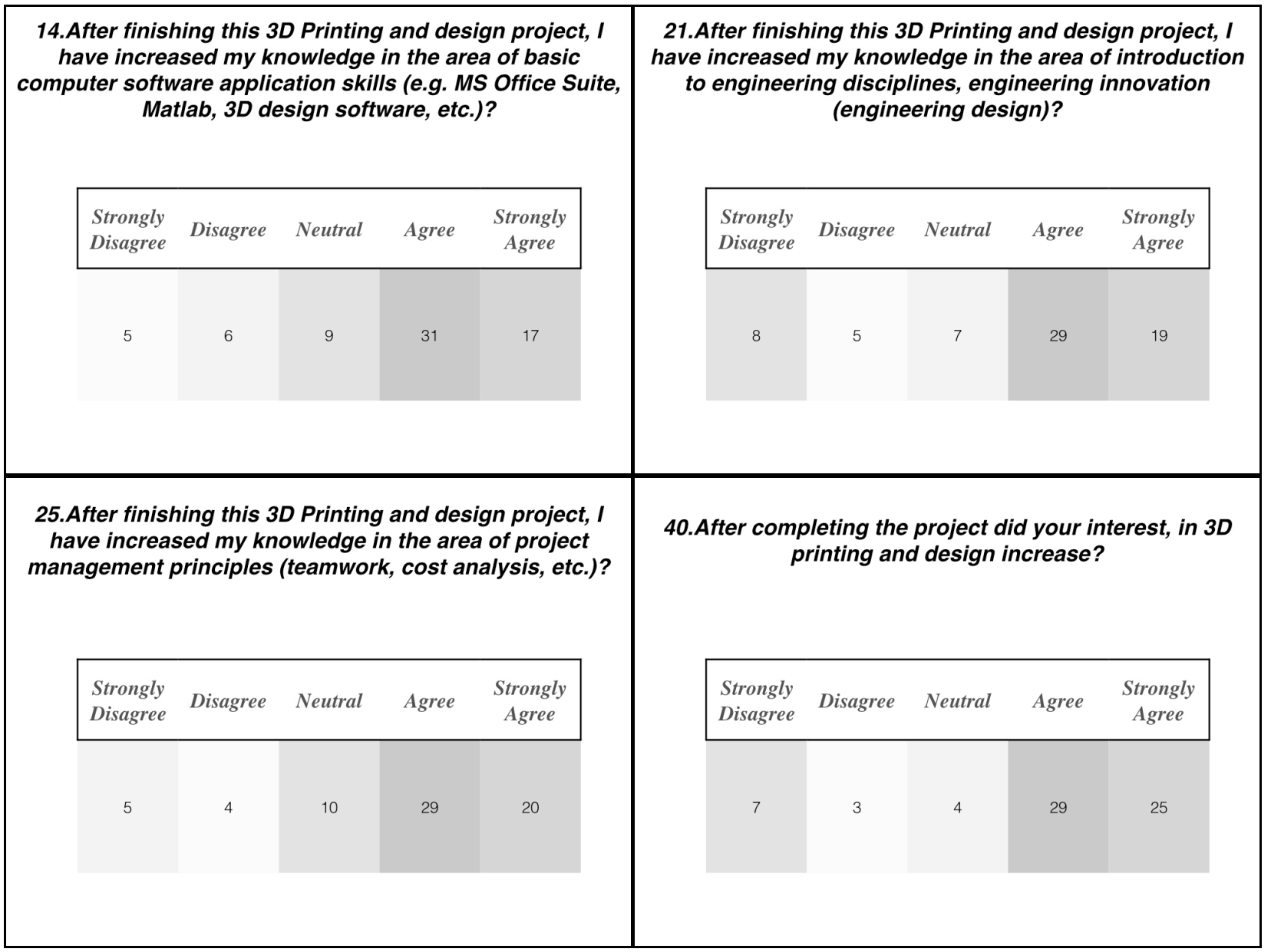

Figure 3. Multiple-choice section of survey on knowledge gained $(\mathrm{n}=68)$

Figure 3 shows four sample questions presented to the students after the semester ended. These four questions are the ones in which more than $70 \%$ of the students agree and strongly agree on the answer. Due to this fact these questions where cataloged as higher impact. 


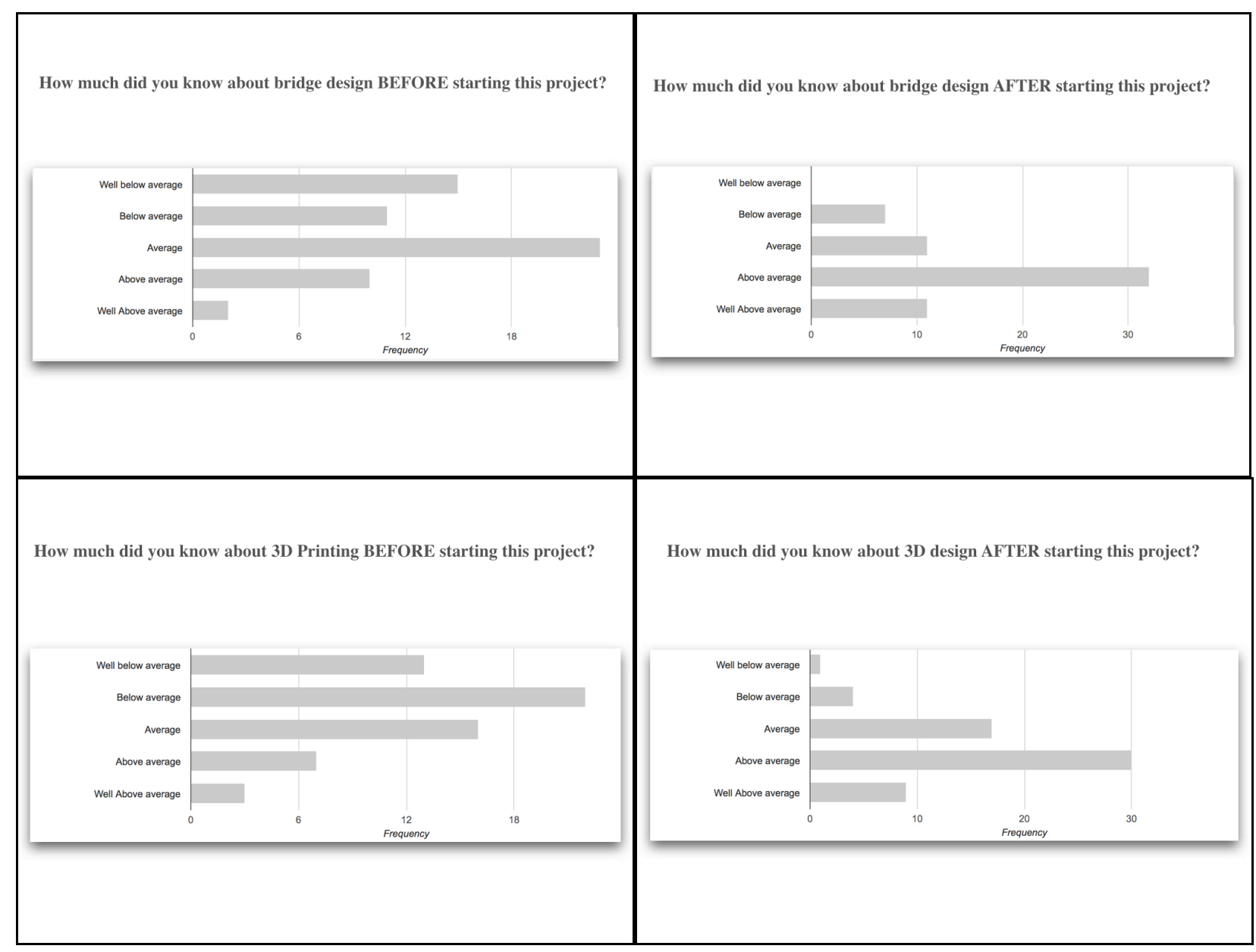

Figure 4. Section of survey on 3D printing and bridge design $(n=68)$ 


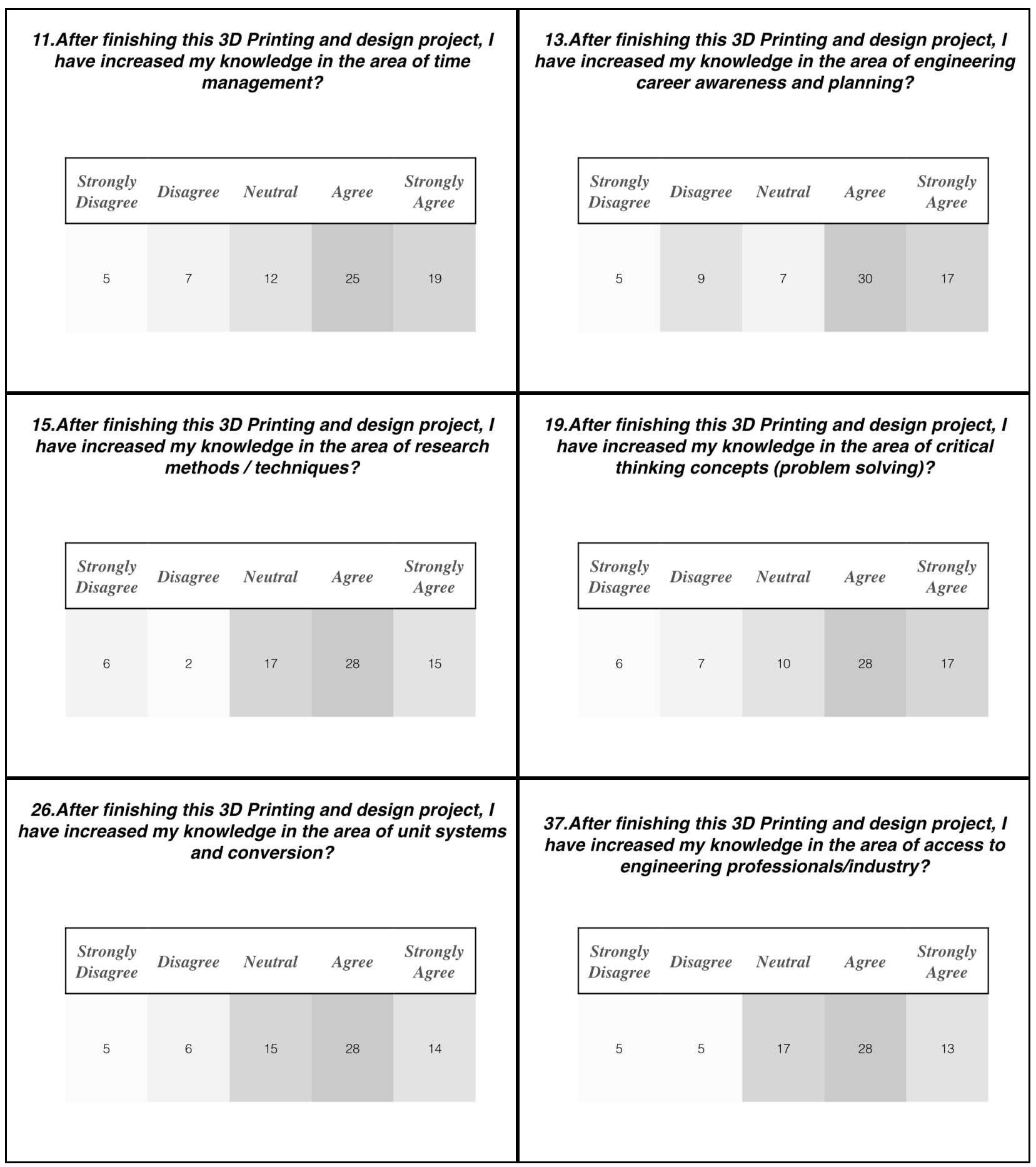

Figure 5. Multiple-choice section of survey on knowledge gained $(\mathrm{n}=68)$

\section{DISCUSSION}

The first result up for discussion is the fact that Classes B, C and D performed better than Class A during the second 6 weeks of the course. The 3D technology projects were assigned during these second six weeks. After a more in depth analysis of these results it can be seen that on the first 
exam Class B performed 4.57 (four and a half points) points above Class A, Class C performed 7.07 (seven) points better than Class A, and Class D performed 5.62 (five and a half) points below Class A. If everything is maintained constant, it would be expected that for the second six weeks Class B would perform four and a half points above Class A; Class $\mathrm{C}$ would perform seven points above Class A; and Class D would perform five and a half points below Class A. Analyzing the rest of the results in Table 1, it can be clearly seen that Class B has outperformed Class A in exam II by 5.80 points, Class C outperformed Class A by 27.13 points, and Class D outperformed Class A by 19.51 points. If the four-point five, seven-point and negative five and a half-point difference without technology were taken into account, this difference for exam II would be around $\mathbf{1 . 2 3}$ improvement points for Class B, 20 improvement points for Class $\mathrm{C}$, and 25 improvement points for Class D. This could be attributed to specific topics where the 3D technology was used extensively during the second six weeks such as: 2D and 3D vectors, area and volume calculations, and material density calculations that were tested during exam II. Figures 1 and 2 describe the student grade letter percentage distribution of exams I and II.

After analyzing the results of the attitudinal survey, it can be seen that the students perceived an increase in knowledge. The results displayed in Figure 3 support the statement that the 3D technology project had a positive impact on other areas such as basic computer software applications, engineering innovation, engineering disciplines, and project management principles. Figure 3 also shows that the students increased their interest in 3D printing and design (question 40). The four questions shown represent the areas in which this 3D project had the bigger impact according to student perception.

The students see the impact of the 3D technology printing and design projects as a positive factor in their learning. The results displayed in Figure 4 support the previous statement. The change in the students' perception of how much they learned dramatically shifted towards the above average and well above average categories after the implementation of the $3 \mathrm{D}$ technology project.

Another set of questions in which the majority of the students agree on their perceived learning is shown in Figure 5. In this set of questions the agreement of the students was higher than $60 \%$ and lower than $70 \%$. Here we can see that the 3D technology project had a high impact in the areas of time management, engineering career awareness and planning, research methods and techniques, critical thinking concepts, and unit systems and conversions. From previous research we have confirmed the fact that engineering students with the demographics of The University of Texas at El Paso prefer a class that uses technology.

Finally, from the attitudinal survey, as a whole, the majority of the students were actively engaged in the different activities required to do the $3 \mathrm{D}$ technology project. Comments like the following were written on the open-ended questions of the survey:

- Question 48. What new technical and engineering concepts did you learn from this project?

○ "I learned how to use the software for the $3 \mathrm{~d}$ printer and how to develop a design."

- "I learned about the concept of weight distribution in structures."

- "I learned on how to create a 3D design using the inventor"

- Question 54. What was your favorite part about 3D bridge project?

○ "Designing it and seeing a final product."

○ "My favorite part was to ACTUALLY WATCH MY FINAL DESIGN PRINTED OUT!"

○ "how the $3 \mathrm{~d}$ printer actually works." 
From this analysis it can be can determined that new technologies can be used to engage students in learning and that students not only like the usage of technology in their coursework but also prefer courses that use cutting-edge technologies in the classroom.

\section{CONCLUSION}

Finally, this study was conducted in a framework that represents UTEP demographics in an entrylevel engineering course. From this study we can conclude that the class average increased in the three classes that implemented the 3D technology project. A strong argument can be made that because Class B started 4.5 points above Class A, the absolute impact is an increase of 1.5 points on exam 2 for Class B, 20 points for Class C, and 25 points for Class D in comprehension of learning outcomes. This is attributed to the applications that were used in the $3 \mathrm{D}$ technology project such as 2D and 3D vector analysis, unit conversion, area and volume calculations, and engineering design method and density calculations. Students' perceived value and learning impact of having used a 3D printer for the course was very positive for the first year of the ongoing research. In summary, the use of the 3D printer increased the students' academic performance when its use was closely tied to the class content. For the most part there was a highly positive impact of the students' perceived value of using a 3D printer in the classroom, which positively affected the classroom environment. The price of the printer was \$2300 USD and it impacted more than 70 first year engineering students, the majority in a positive way. The 3D printer will continue to be used for consequent classes; therefore as more and more students use it, the cost per student will continue to decrease (at this point is about $\$ 32.85$ USD per student).

\begin{tabular}{|c|c|c|c|c|r|}
\hline \multicolumn{7}{|c|}{ University 1301 Course } \\
\hline Instructor & Team Name & $\begin{array}{c}\text { Build Time } \\
\text { ( Hours) }\end{array}$ & Resolution & $\begin{array}{c}\text { Material Used } \\
\text { (Grams) }\end{array}$ & Cost pe design \\
\hline Hugo Gomez & The Beatles & $8 \mathrm{~h} \mathrm{13m}$ & $0.2 \mathrm{~mm}$ & 89.03 & $\$ 2.67$ \\
\hline Hugo Gomez & Bridge Team & $8 \mathrm{~h} 47 \mathrm{~m}$ & $0.2 \mathrm{~mm}$ & 83.6 & $\$ 2.51$ \\
\hline Hugo Gomez & 3D Bridge & $7 \mathrm{~h} 26 \mathrm{~m}$ & $0.2 \mathrm{~mm}$ & 78.68 & $\$ 2.36$ \\
\hline Oscar Perez & Bridge 2 & $6 \mathrm{~h} 16 \mathrm{~m}$ & $0.2 \mathrm{~mm}$ & 66.89 & $\$ 2.01$ \\
\hline Oscar Perez & Bridge in nators & $4 \mathrm{~h} 44 \mathrm{~m}$ & $0.2 \mathrm{~mm}$ & 47.31 & $\$ 1.42$ \\
\hline Oscar Perez & Epsilon Team & $8 \mathrm{~h} 51 \mathrm{~m}$ & $0.2 \mathrm{~mm}$ & 90.98 & $\$ 2.73$ \\
\hline Oscar Perez & Final Bridge & $7 \mathrm{~h} 52 \mathrm{~m}$ & $0.2 \mathrm{~mm}$ & 82.97 & $\$ 2.49$ \\
\hline Pedro Espinoza & Bridge & $4 \mathrm{~h} 10 \mathrm{~m}$ & $0.2 \mathrm{~mm}$ & 36.46 & $\$ 1.09$ \\
\hline Pedro Espinoza & Epsilon Bridge & $8 \mathrm{~h} 45 \mathrm{~m}$ & $0.2 \mathrm{~mm}$ & 89.26 & $\$ 2.68$ \\
\hline Pedro Espinoza & Team 3 & $2 \mathrm{~h} 50 \mathrm{~m}$ & $0.2 \mathrm{~mm}$ & 26.52 & $\$ 0.80$ \\
\hline Pedro Espinoza & The Trolls & $11 \mathrm{~h} \mathrm{38m}$ & $0.2 \mathrm{~mm}$ & 144.83 & $\$ 4.34$ \\
\hline Pedro Espinoza & Univ Bridge & $12 \mathrm{~h} 59 \mathrm{~m}$ & $0.2 \mathrm{~mm}$ & 162.22 & $\$ 4.87$ \\
\hline
\end{tabular}

Table 2. 3D team designs characteristics 
Table 2 above shows the amount of PLA material used for each of the designs, the time it took to print each and the actual cost per design based on the material used.

\section{FUTURE WORK}

More work needs to be done on the lasting impacts of the concepts taught during Exam 2 (i.e. does the perceived value of a $3 \mathrm{D}$ printer on specific course objectives substantially impact content retention of those concepts later in the students' academic career?) As we progress into the second year of this ongoing research, some of the questions to be addressed include long-term analysis of the following questions: does engaging a student with technology on a difficult learning objective give them better mastery of that content area later in the academic career; how does changing the perceived value of a course with technology impact the long-term perception of students value of essential learning objectives and their performance and mastery of them throughout their career; does exciting students early on with technology such as 3D printers increase the chances of them graduating due to positive first semester engagements with the content?

Future work planned for this ongoing research should expand to the following areas: 1) development of smaller 3D designs to cut down the time to print; 2) acquisition of a second printer to speed up printing time and/or reduce the number of students per team; and 3) the implementation of the $3 \mathrm{D}$ printer across different engineering areas in higher-level engineering classes.

\footnotetext{
${ }^{1}$ Jacobsen, D. M., "Adoption patterns of faculty who integrate computer technology for teaching and learning in higher education," 1998 World Conference on Educational Multimedia and Hypermedia \& World Conference on 2 Gibbons, M. T., "The Year in Numbers," 2007 Profiles of Engineering and Engineering Technology Colleges, Washington, DC: The American Society for Engineering Education, 2008.

${ }^{3}$ Brown C., Johnson M., Lax J., "Educational Classroom Technology: What Works Best in the Engineering Context", 2007, 37th ASEE/IEEE Frontiers in Education Conference, Session S4J.

${ }^{4}$ Grady, H., and Codone, S., " From chalkboard to PowerPoint to the web: A continuum of technology," 2004 International Professional Communication Conference, pp. 217-222.

5 B. Flores, "CAMPUS DIVERSITY FACTS", http://research.utep.edu/Default.aspx?tabid=44271, 1995-2007, (accessed 4/1/2015).
} 